"Das Band der ewigen Liebe" 


\section{Clara Schumann}

»Das Band

Briefwechsel der ewigen mit Emilie und Elise List Lebe herausgegeben von Eugen Wendler 
Die Deutsche Bibliothek - CIP-Einheitsaufnahme

„Das Band der ewigen Liebe : Briefwechsel mit Emilie und Elise List / Clara Schumann.

Hrsg. von Eugen Wendler. - Stuttgart ; Weimar : Metzler, 1996

ISBN 978-3-476-01453-5

NE: Schumann, Clara; List, Emilie; List, Elise; Wendler, Eugen [Hrsg.]

ISBN 978-3-476-01453-5

ISBN 978-3-476-03661-2 (eBook)

DOI 10.1007/978-3-476-03661-2

Dieses Werk einschließlich aller seiner Teile ist urheberrechtlich geschützt. Jede Verwertung außerhalb der engen Grenzen des Urheberrechtsgesetzes ist ohne Zustimmung des Verlages unzulässig und strafbar. Das gilt insbesondere für Vervielfältigungen, Übersetzungen, Mikroverfilmungen und die Einspeicherung und Verarbeitung in elektronischen Systemen.

(C) 1996 Springer-Verlag GmbH Deutschland

Ursprünglich erschienen bei J.B. Metzlersche Verlagsbuchhandlung und Carl Ernst Poeschel Verlag GmbH in Stuttgart 1996 


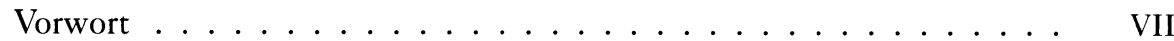

Die Familien-Bekanntschaft

und Freundschaft List-Schumann. . . . . . . . . . . . . . . . 1

Die Briefe . . . . . . . . . . . . . . . . . . . . . . 39

Friedrich List und seine Familie . . . . . . . . . . . . . . . . . . . 435

I. Immer nur aus dem Groben gesungen . . . . . . . . . . . 437

II. Ein Anwalt ohne Sold, bemüht fürs Vaterland . . . . . . . . . . 441

III. Karoline - die Frau mit der himmlischen Sanftmut . . . . . . 452

IV. Emilie-die treue Seele . . . . . . . . . . . . . . . 458

V. Oskar - ein junger Mann voller Herzensgüte . . . . . . . . . 468

VI. Elise - die stille Schönheit . . . . . . . . . . . . . . . . . . . 470

VII. Lina - die talentierte Malerin . . . . . . . . . . . . . . 497

Literaturverzeichnis . . . . . . . . . . . . . . . 503

Ortsverzeichnis . . . . . . . . . . . . . . . . 506

Namenverzeichnis . . . . . . . . . . . . . . . 511 
Für Christl 


\section{Vorwort}

Drei Frauengestalten des 19. Jahrhunderts stehen im Mittelpunkt dieser Korrespondenz: die bekannte Pianistin und Komponistin Clara Schumann und die beiden ältesten Töchter des Nationalökonomen Friedrich List - Emilie und Elise. Sie lernten sich in ihrer Jugendzeit in Leipzig kennen. Aus der Jugendfreundschaft entwickelte sich eine rund 60jährige Lebensfreundschaft.

Die drei Freundinnen verkörpern völlig unterschiedliche Frauentypen: die früh verwitwete Mutter einer kinderreichen Familie, deren wichtigster Lebensinhalt der Künstlerberuf war, in dem sie nicht nur als Pianistin und Komponistin außergewöhnliche künstlerische Glanzleistungen hervorbrachte, sondern auch als eigene Konzertagentin überragendes Organisationstalent entwickelte; dann die unverheiratete bürgerliche Haustochter, die sich für ihre Familienangehörigen aufopferte und schließlich die wohlhabende, ebenfalls früh verwitwete adelige Bürgerstochter, der es wegen unüberwindlicher psychischer Hemmungen versagt geblieben ist, den ersehnten Künstlerberuf als Sängerin auszuüben.

Ihre Freundschaft kann erst jetzt dokumentiert werden, nachdem der Herausgeber die Erlaubnis erhalten hatte, die Privatsammlung Cornides, in der sich der größte Teil der umfangreichen Korrespondenz Clara Schumanns mit den List-Töchtern befindet, wissenschaftlich auszuwerten. Die Sammlung befand sich im Besitz des Wiener Verlegers Dr. Karl Cornides v. Krempach - einem Ururenkel von Friedrich List. Er übergab die Sammlung Anfang der 80er Jahre dem Archiv der Gesellschaft der Musikfreunde in Wien, behielt sich aber das Verfügungs- und Editionsrecht vor. Nach seinem Tode sind diese Rechte auf seine Kinder Dr. Thomas Cornides in Wien/München und Frau Elisabeth Garms-Cornides in Rom übergegangen. Beide haben mir freundlicherweise ihre Zustimmung zur Aufarbeitung und Edition der Korrespondenz erteilt. Dafür möchte ich mich sehr herzlich bedanken.

Die Sammlung Cornides umfaßt ca. 250 Briefe und Korrespondenz-Postkarten. Darüberhinaus konnten aus öffentlichen und privaten Archiven etwa 60 weitere Briefe sowie zahlreiche andere erläuternde Dokumente zusammengetragen werden, soda $\beta$ die gesamte jetzt bekannte Korrespondenz mehr als 300 Schriftstücke umfaßt und durch eine Vielzahl von unbekannten Quellen erweitert und bereichert werden konnte. Hierfür möchte ich vor allem folgenden Archiven meinen besten Dank aussprechen: 
- Paul Sacher Stiftung Basel

- Staatsbibliothek Preussischer Kulturbesitz Berlin

- Robert-Schumann-Forschungsstelle Düsseldorf

- Heinrich-Heine-Institut Düsseldorf

- Universitätsbibliothek Heidelberg

- Biblioteka Jagiellonska Krakau

- Universitätsbibliothek Leipzig

- Stadtgeschichtliches Museum Leipzig

- Deutsches Literaturarchiv/Schiller-Nationalmuseum Marbach

- Bayerische Staatsbibliothek München

- Deutsches Museum München

- Stadt- und Listarchiv Reutlingen

- Josef Rheinberger-Archiv Vaduz

- Library of Congress Washington

- Bibliothek der Nervenheilanstalt Werneck

- Gesellschaft der Musikfreunde Wien/Sammlung Dr. Cornides

- Robert Schumann-Haus Zwickau

Alle Briefe, bei denen kein Aufbewahrungsort vermerkt ist, gehören zur Sammlung Cornides, die sich - wie bereits erwähnt - als privates Depositum im Archiv der Gesellschaft der Musikfreunde in Wien befindet. Lediglich bei den Briefen, die aus anderen Archiven stammen, ist der Fundort in der Fußnote angegeben. Bei der Transkription wurden die Eigentümlichkeiten der Orthographie und Interpunktion weitgehend beibehalten. Unterstrichene Briefstellen sind in Kursivschrift wiedergegeben.

Bei der Transkription und datentechnischen Übertragung der Briefe war mir Frau Brigitte Digel, Kulturwissenschaftlerin M.A., im Rahmen einer ABM-Stelle behilflich. Ihre Anstellung wurde durch die finanzielle Unterstützung der Karl-Danzer-Furnierwerke Reutlingen, der Firma Resicoat Reutlingen sowie der Volksbank Reutlingen ermöglicht. Dafür bin ich Herrn KarlHeinz Danzer, Herrn Manfred Walther und Herrn Dr. Rainer Märklin mit tiefempfundenem Dank verbunden. Ohne ihre Förderung hätte das Editionsprojekt nicht begonnen werden können.

Nach dem Wegfall der ABM-Stelle war ich weitgehend auf mich allein gestellt; nur durch die ehrenamtliche Mithilfe von Frau Roswitha Cammarota und Herrn Dipl.-Betriebswirt (FH) Alexander Stirm war es möglich, das umfangreiche Projekt zu einem erfolgreichen Abschluß zu bringen. Ich danke beiden recht herzlich für ihre verständnisvolle, geduldige und engagierte Mitarbeit.

Herrn Bruno Zeeb bin ich für das Korrekturlesen und die Erstellung des Personen- und Ortsregisters mit großem Dank verbunden. Frau Dr. Karin Bormann hat beim Personen- und Ortsregister mitgeholfen. Dem Reutlinger Musikwissenschaftler Prof. Dr. Eberhard Stiefel habe ich für die musikwissenschaftliche Beratung zu danken. 
Mein besonderer Dank gilt dem Robert-Schumann-Haus in Zwickau, seinem Leiter Herrn Dr. Gert Nauhaus und ganz besonders Frau Renate Roßner, die sich der Mühe unterzogen hat, das gesamte Manuskript zu lesen und mir bei den kommentierenden Fußnoten in vielfacher Hinsicht wertvolle Dienste leistete. In gleicher Weise möchte ich der Robert-Schumann-Forschungsstelle e. V. in Düsseldorf, insbesondere Herrn Dr. Bernhard R. Appel und Herrn Dr. Matthias Wendt für ihre wertvollen Hinweise und den großen persönlichen Einsatz zur Drucklegung meinen besten Dank aussprechen.

Mein innigster Dank gilt meiner lieben Christl. Ohne ihr Verständnis für den mühevollen und beträchtlichen Zeitaufwand und die vielfältigen Anstrengungen, die es zur Fertigstellung dieses Vorhabens bedurfte, hätte das Projekt nicht zum Abschluß gebracht werden können. Ihr sei diese Arbeit von Herzen gewidmet.

Reutlingen, den 1. Januar 1996

Eugen Wendler 